\title{
A Novel Linear Electromagnetic-Drive Oil-Free Refrigeration Compressor using R134a
}

\author{
Kun Liang*, Richard Stone, Mike Dadd, Paul Bailey \\ Department of Engineering Science, University of Oxford, Oxford, UK, OX1 3PJ \\ ${ }^{*}$ Corresponding author. Tel: +44 1865283093. \\ Email address: kun.liang@eng.ox.ac.uk (K. Liang)
}

\begin{abstract}
A new type of oil-free moving magnet linear compressor with clearance seals and flexure springs has been designed for incorporation into a vapour compression refrigeration system with compact heat exchangers for applications such as electronics cooling. A linear compressor prototype was built with a maximum stroke of $14 \mathrm{~mm}$ and a piston diameter of $19 \mathrm{~mm}$. An experimental apparatus was built to measure the compressor efficiencies and coefficient of performance (COP) of a refrigeration system with the linear compressor, using R134a. The resonant frequency for each operating condition was predicted using the discharge pressure, suction pressure and stroke. Refrigeration measurements were conducted for different strokes under each pressure ratio with a fixed condenser outlet temperature of $50{ }^{\circ} \mathrm{C}$ and evaporator temperature ranging from $6{ }^{\circ} \mathrm{C}$ to $27^{\circ} \mathrm{C}$. The results show that the COPs are around 3.0 for tests with a pressure ratio of 2.5 (evaporator temperature of $20^{\circ} \mathrm{C}$ ).
\end{abstract}

Keywords: Oil-free, moving magnet motor, refrigeration, linear compressor, resonance, COP 


\section{NOMENCLATURE}

$\begin{array}{ll}A & \text { area }\left(\mathrm{m}^{2}\right) \\ C L & \text { clearance ratio } \\ \text { COP } & \text { coefficient of performance } \\ \text { CPU } & \text { central processing unit } \\ \text { DC } & \text { direct current } \\ f & \text { frequency }(\mathrm{Hz}) \\ F & \text { force }(\mathrm{N}) \\ h & \text { enthalpy }\left(\mathrm{kJ} \mathrm{kg}^{-1}\right) \\ I & \text { current }(\mathrm{amp}) \\ k & \text { stiffness }\left(\mathrm{N} \mathrm{m}^{-1}\right) \\ \text { LVDT } & \text { linear variable differential transformer } \\ m & \text { moving mass }\left(\mathrm{kg}^{-1}\right. \\ \dot{m} & \text { mass flow rate }\left(\mathrm{g} \mathrm{s} \mathrm{S}^{-1}\right) \\ n & \text { polytropic index } \\ P & \text { pressure (bar) } \\ p-h & \text { pressure-enthalpy } \\ \text { PM } & \text { power meter } \\ P R & \text { pressure ratio } \\ \text { PS } & \text { pressure switch } \\ \mathrm{PT} & \text { pressure transducer } \\ P-V & \text { pressure-volume } \\ \dot{Q} & \text { cooling capacity }(\mathrm{W}) \\ R & \text { resistance }(\Omega) \text { or specific gas constant }\left(\mathrm{J} \mathrm{kg}^{-1} \mathrm{~K}^{-1}\right) \\ \text { RMS } & \text { root mean square } \\ S & \text { stroke (mm) } \\ T & \text { temperature }\left({ }^{\circ} \mathrm{C}\right) \\ \text { TC } & \text { thermocouple } \\ \dot{W} & \text { rate of compression work }(\mathrm{W}) \\ x & \text { displacement } \\ & \end{array}$

\section{Greek letter}

$\begin{array}{ll}\varepsilon & \text { normalised COP } \\ \eta & \text { efficiency }\end{array}$

\section{Subscripts}

$\begin{array}{ll}\text { cond } & \text { condenser } \\ \text { cool } & \text { cooling } \\ \text { dis } & \text { discharge } \\ \text { e } & \text { experimental } \\ \text { evap } & \text { evaporator } \\ \text { g } & \text { gas } \\ \text { isen } & \text { isentropic } \\ \text { m } & \text { mechanical } \\ \text { p } & \text { piston } \\ \text { suc } & \text { suction } \\ \text { V } & \text { volumetric }\end{array}$




\section{Introduction}

As has been indicated by Davies et al. (2010) and Bailey et al. (2009), there is a need to improve the capabilities of cooling technology to dissipate increasingly high heat fluxes (approaching $200 \mathrm{Wcm}^{-2}$ ) from electronic components in order to maintain acceptable operating temperatures. Possible alternative cooling technologies for electronics have been reported by Bailey et al. (2009). One desirable approach is to use vapour cycle refrigeration circuits with evaporators that have miniaturised heat exchange surfaces. Barbosa et al. (2012) have recently reviewed compact vapour compression refrigeration systems and their applications.

Bradshaw et al. (2011) and Bailey et al. (2011) pointed out that the linear compressor is an attractive proposition for electronics cooling applications because it offers several benefits compared to traditional compressor technology. A linear compressor does not have a crank mechanism to drive the piston and is driven directly by a linear motor, which has a higher electrical efficiency than a traditional rotary induction motor. Oil-free operation is possible, and this is a significant advantage with respect to the heat transfer performance of the condenser and the evaporator in a refrigeration system and it would allow the use of compact heat exchangers. The absence of oil widens both the choice of refrigerants and their operating temperature range. In a high efficiency linear machine, the piston operates resonantly in order to minimise the drive current and ohmic losses. Bradshaw (2012a) concluded that the potential for this technology to be scaled to small physical sizes is better than for conventional compressors.

Recent developments with linear compressors have been presented by Liang et al. (2013a). Aiming to design small scale refrigeration systems for electronics cooling, a number of linear compressors have been incorporated into vapour compressor refrigeration units with compact heat exchangers (evaporator and condenser). Bradshaw et al. (2011) presented a model of a miniature-scale linear compressor for electronics cooling. The prototype linear compressor was driven by a commercial moving magnet type linear motor (H2W Tech) of which the electrical efficiency was assumed to be $41.7 \%$. Bradshaw et al. (2012b) used the model to predict the linear compressor performance with a smaller stroke-to-diameter ratio which showed a higher isentropic efficiency than Bradshaw et al. (2011). Unger et al. (2002) introduced a compact moving magnet linear compressor, with a high performance linear motor. Operated at $95 \mathrm{~Hz}$ for a $1250 \mathrm{~W}$ cooling capacity using R134a, the COP was 3.6 when the evaporator and condenser temperatures were $20^{\circ} \mathrm{C}$ and $55^{\circ} \mathrm{C}$, respectively. Kim et al. (2009) simulated the resonance and experimentally measured the effect of system resonance on the performance of a linear compressor which used the Sunpower design of linear compressor (Unger and Novotny, 2002), working with R600. This linear compressor has a stroke of $15.2 \mathrm{~mm}$, a piston diameter of $30.5 \mathrm{~mm}$, and a motor constant of $93.6 \mathrm{NA}^{-1}$. The variation of the COP was about $3 \%$ when the operating frequency varied from $48.5 \mathrm{~Hz}$ (off-resonance) to the resonant frequency of $50 \mathrm{~Hz}$. Chen et al. (2007) built a prototype linear compressor employing a Sunpower moving magnet motor design with a maximum stroke of $10 \mathrm{~mm}$, a cylinder diameter of $45 \mathrm{~mm}$, and a working gas of helium. It was found that the stroke was approximately a linear function with the input voltage and that the optimal working frequency should be slightly lower than its resonant frequency. Possamai et al. (2008) developed a prototype refrigeration system for a laptop cooling application utilizing micro-channel type heat exchangers for both the evaporator and condenser, and a moving magnet linear compressor designed by Embraco. The linear motor efficiency was about $71 \%$ and the isentropic compression efficiency was about $42 \%$, working with R600a at high operating frequencies. 
The University of Oxford has been involved in developing linear machines since the 1970's. Liang et al. (2013a) have described the three generations of linear compressor (with moving coil type motors) designed for Stirling and pulse tube systems in space applications. Bailey et al. (2009) further discussed the obstacles to extend the technology to other applications and the drawbacks of moving coil linear motors themselves. These factors led to the design of a novel moving magnet linear compressor for a project in collaboration with London South Bank University and Newcastle University, to develop a complete system suitable for computer cooling. Liang et al. (2013a) and (2013b) discussed the design of the compressor and the preliminary experimental evaluation using nitrogen. Fig. 1 shows the assembled linear compressor, consisting of a moving magnet linear motor, a flexure spring suspension system and the piston-cylinder assembly. There are two identical compressor halves (compressors 1 and 2) mounted in line, operating in opposite directions to reduce vibrations. Table 1 gives the design specification of the linear compressor. The spring arm first resonance is at $497 \mathrm{~Hz}$, which is well above the drive frequency.

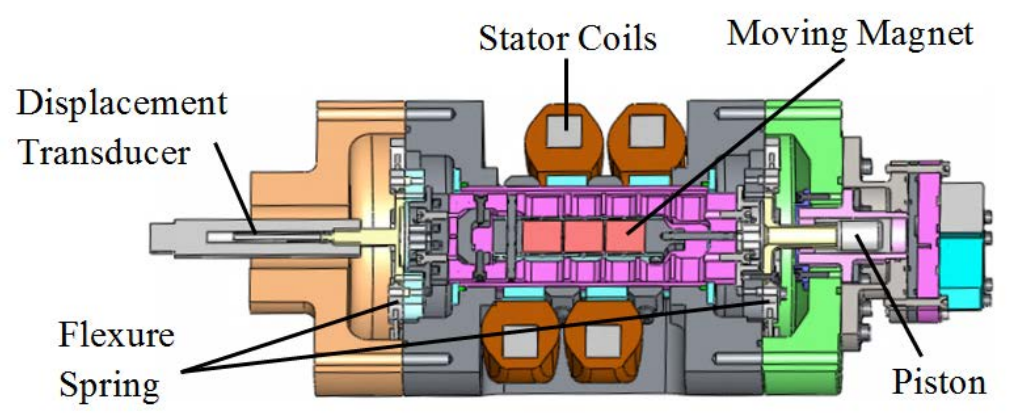

Fig.1 Moving magnet linear compressor configuration

Table 1 Linear compressor design specification (Liang et al., 2013a)

\begin{tabular}{lc}
\hline Total mass of magnet/piston, $m(\mathrm{~kg})$ & 0.66 \\
Piston diameter $(\mathrm{mm})$ & 18.99 \\
Total series $^{1}$ resistance of coils $(\Omega)$ & 14 \\
Peak shaft force $(\mathrm{N})$ & 84 \\
Peak current at peak force $(\mathrm{A})$ & 1.29 \\
Flexure stiffness, $k_{\mathrm{m}}\left(\mathrm{kNm}^{-1}\right)$ & 17 \\
Maximum stroke $(\mathrm{mm})$ & 14 \\
\hline
\end{tabular}

${ }^{1}$ The four motor coils were connected with two coils in series then each pair in parallel to give a resistance of $\sim 3.5 \Omega$ for each compressor half (see Fig. 3).

\section{Experimental Apparatus}

\subsection{Test Rig}

Fig. 2 shows the experimental refrigeration apparatus for the linear compressor using R134a. The high temperature and pressure gas from compression was discharged into a heat exchanger (condenser). A needle valve (main flow valve) controlled the pressure ratio, followed by another heat exchanger with an electric heater acting as an evaporator. This system comprised the main flow loop. In the meantime, the bleed valve controlled the pressure in the compressor body so as to maintain the correct mean piston position.

The discharge pressure, body pressure, suction pressure and evaporator inlet pressure were measured using pressure transducers (Druck PMP 1400). K-type thermocouples were used to measure the body temperature, coil temperature, discharge temperature, condenser outlet temperature, evaporator inlet and outlet temperatures, and suction temperature. The main flow was measured using a mass flow 
meter (Hastings HFM-201) while a Tylan FM-360 mass flow meter was used for the bleed flow measurement.

The compressor was warmed up by directly mounting four resistors $(0.22 \Omega)$ in series to the compressor body, with a DC power supply to prevent the refrigerant from condensing in the motor space. For safety reasons, two pressure switches were used with the electrical heater in the evaporator in case the discharge pressure exceeded 17 bar or the suction pressure was less than 2 bar. In order to control the condenser temperature in the refrigeration system, a constant head method was employed to obtain a steady water flow through the condenser. The water flow rate was measured using a Rotameter. The input to the electrical heater in the evaporator was measured using a power meter. One sight glass was used to monitor the state of the fluid leaving the condenser while the other one monitored the fluid leaving the evaporator.

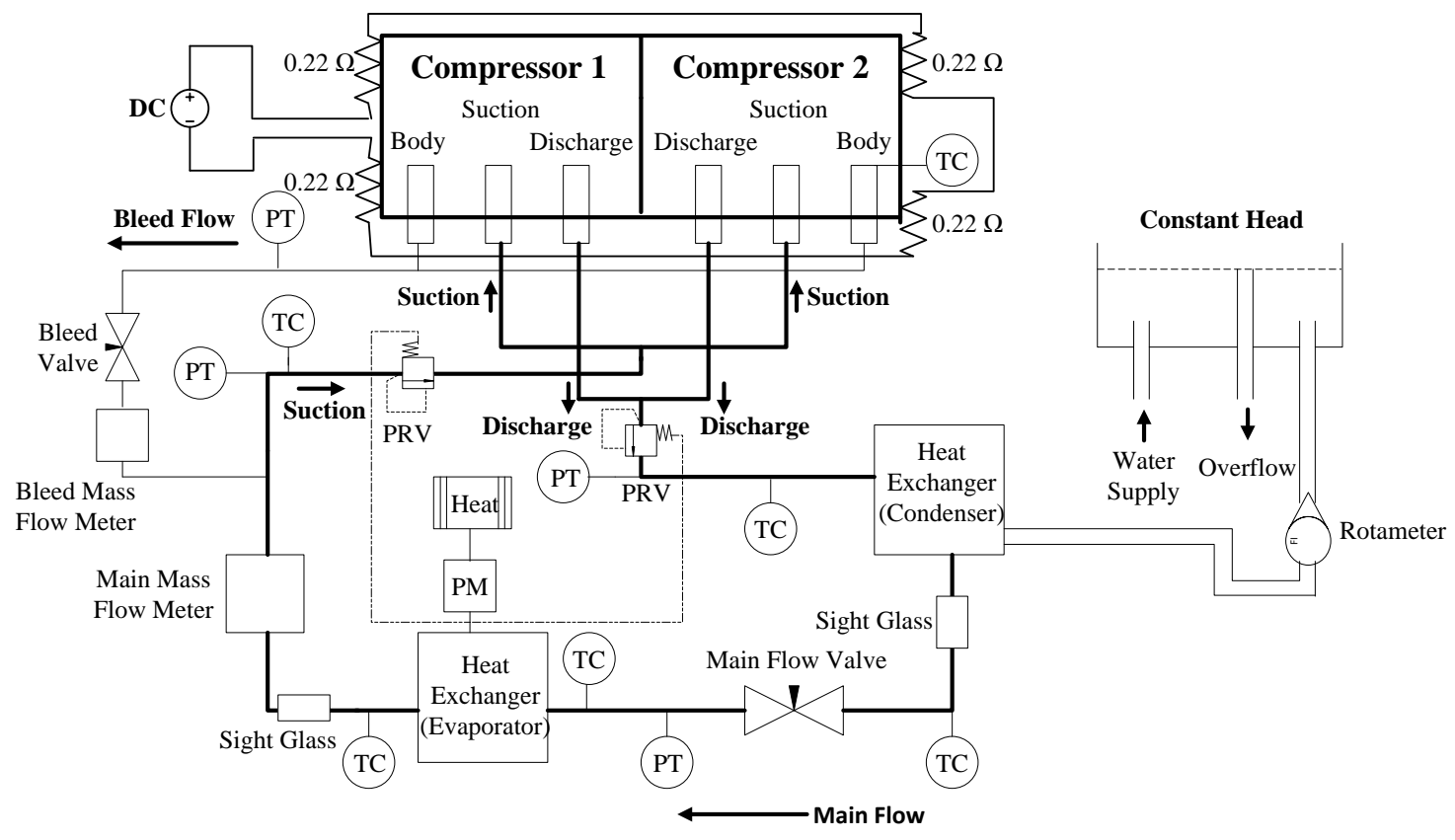

Fig. 2 Linear compressor refrigeration test loop (TC: Thermocouple, PT: Pressure Transducer, PS: Pressure Switch, PM: Power Meter, DC: Direct Current)

The power supply and compressor control system are shown in Fig. 3. The bold line shows the power flow into the compressor. The signal generator defined the drive frequency and a separate fine amplitude control can be used to set the piston stroke as intended. A power amplifier then amplified the analogue signal to drive the linear compressor. A safety box set the safe ranges for signals from: the two displacement transducers, the discharge pressure, the suction pressure and the evaporator inlet temperature, so that if any signal was out of range, the compressor power supply as well as the electric heater to the evaporator would be cut off. A power analyser displayed the power input to the compressor, and the current and voltage RMS values. The current transducer and voltage sensor measured the real-time current (for each compressor half) and voltage respectively. A panic button could be manually pressed if there was any emergency so that the power supply would be cut off. A capacitance box permitted adjustment of the capacitance for different operating frequencies - this power factor correction reduced the voltage requirement for the amplifier. LVDTs were employed to measure the displacement signals from each compressor half. Two resistors of $0.1 \Omega$ were placed separately in series with the top and bottom coils for each compressor half. These were used to 
monitor the currents separately in the top and bottom coils as they were connected in parallel and could be different.

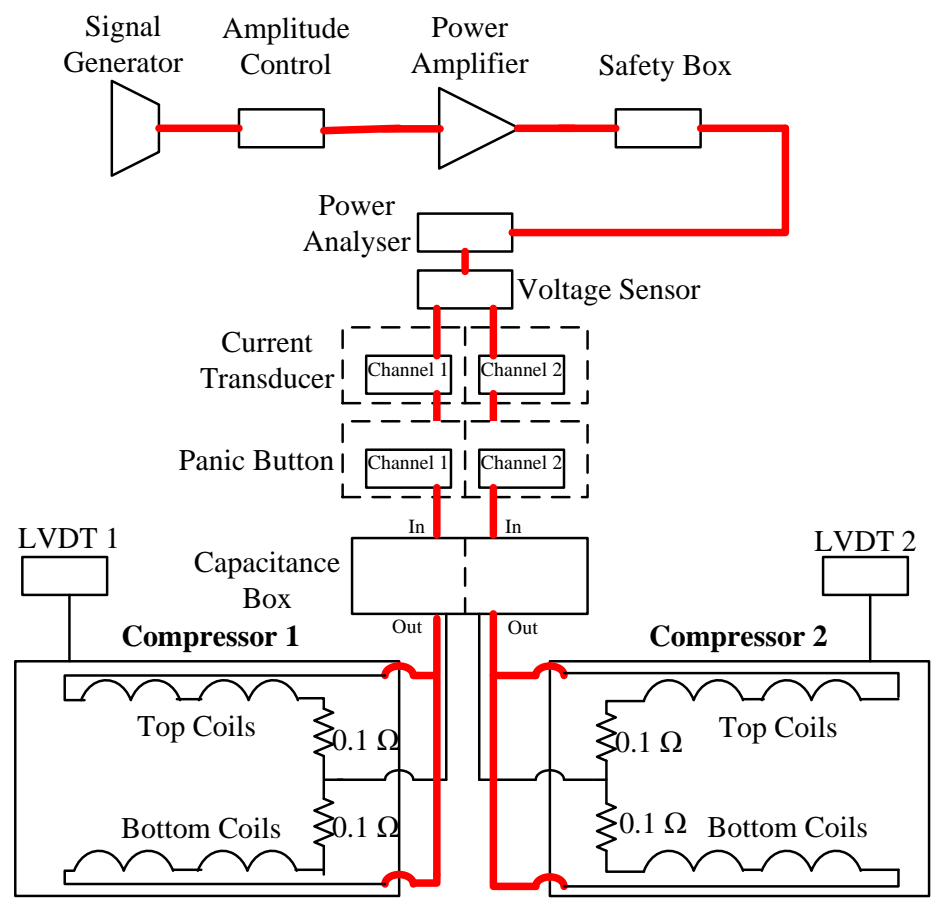

Fig. 3 Compressor control and power supply instrumentation (LVDT: Linear Variable Differential Transformer, displacement transducer)

\subsection{Test Conditions}

In the refrigeration experiment with the linear compressor using R134a, there were many variables to control, e.g. stroke, pressure ratio, electrical heat input, piston mean position, suction temperature, and condenser temperature. Because of the many interdependencies, the tests were simplified by keeping the condenser outlet temperature constant at $50^{\circ} \mathrm{C}$ for each test condition (changing the stroke for different pressure ratios). Table 2 gives the specific test conditions of the linear compressor in the refrigeration system.

The test rig was charged with $0.309 \mathrm{~kg}$ of R134a. For each operating point, the stroke and pressure ratio were first manually controlled using the amplitude control and the main flow needle valve. The needle valve changed the mass flow rate to obtain the target pressure ratio. Due to the gas leakage across the seal from the cylinder to the motor space, the mean piston position would vary, depending on the pressure difference. The bleed valve could then be adjusted to control the pressure in the motor space to counter the DC offset. The electrical heater was adjusted to maintain an appropriate suction temperature (superheat of over $5 \mathrm{~K}$ ). The condenser outlet temperature was kept at $50^{\circ} \mathrm{C}$ by changing the cooling water flow rate from the constant head tank. The bleed valve was adjusted to maintain a constant mean piston position for each test condition. The resonant frequency for each test point was manually found by changing the drive frequency of the signal generator and the amplitude control to keep the stroke constant - resonance was assumed to be the frequency at which the power input was a minimum for the specified stroke. With so many variables interdependent in refrigeration experiments, it was difficult to measure the resonance directly. The resonant frequency was calculated from steadystate operational parameters. Previous tests from Liang et al. (2013b) validated a resonance modelling method using the discharge and suction pressure, along with stroke. The steady state operation of the 
refrigeration system was reached when the measured pressures and temperatures along with the mass flow rate were settled, and the sight glasses showed that there was no vapour exiting the condenser and no liquid leaving the evaporator. Typically this required 40 minutes of operation after changing the operating point.

The measured evaporator inlet temperature ranged from $6^{\circ} \mathrm{C}$ to $27^{\circ} \mathrm{C}$.

Table 2 Test conditions using R134a

\begin{tabular}{cc}
\hline Refrigerant charge $(\mathrm{kg})$ & 0.309 \\
Condenser outlet temperature $\left({ }^{\circ} \mathrm{C}\right)$ & 50 \\
Pressure ratio & $2.5,3.0,3.5$ \\
Stroke $(\mathrm{mm})$ & $10,11,12,13$ \\
Evaporator (inlet) temperature $\left({ }^{\circ} \mathrm{C}\right)$ & $6-27$ \\
Suction temperature $\left({ }^{\circ} \mathrm{C}\right)$ & $23-30$ \\
\hline
\end{tabular}

\section{Resonance}

As has been explained by Bradshaw et al. (2011), the stiffness associated with the gas is determined by linearizing the force generated over an entire compression cycle. This gas force is then divided by the stroke of the compressor, which yields an estimate of the effective spring rate of the gas $\left(k_{\mathrm{g}}\right)$ in the compression chamber.

$$
k_{\mathrm{g}}=\frac{P_{\mathrm{suc}}(P R-1) A_{\mathrm{p}}}{S_{\mathrm{p}}}
$$

The total stiffness (including the flexure spring stiffness, $k_{\mathrm{m}}$ from Table 1 ) is

$$
k=k_{\mathrm{g}}+k_{\mathrm{m}}
$$

The resonant frequency $f$ (in $\mathrm{Hz}$ ) can, therefore, be calculated as

$$
f=\frac{1}{2 \pi} \sqrt{\frac{k}{m}}
$$

where $m$ is the moving mass (magnet and piston assembly) given in Table 1 .

Fig. 4 shows the calculated resonant frequencies, as a function of stroke and different pressure ratios for the R134a tests. It is seen that a higher stroke reduces the resonant frequency for a fixed pressure ratio. This is because increasing the stroke means the valves will be open for a greater fraction of the cycle, so that the effective stiffness of the gas is reduced. Generally, for a fixed stroke, a higher pressure ratio produces a higher resonant frequency due to an increase in the gas spring stiffness. When the pressure ratio is 2.5 , the resonant frequency varies by only about $3 \%$ as the stroke increases from 10 to $13 \mathrm{~mm}$. Fig. 4 also shows a comparison between the measured and calculated resonant frequencies for pressure ratios of 2.5 and 3.5. The maximum error between the measured and calculated values is only about $1.5 \%$. Though this approach is an approximation, it has the advantage of simplicity and accuracy so it can be easily adopted for determining the resonant frequency for each operating condition. 


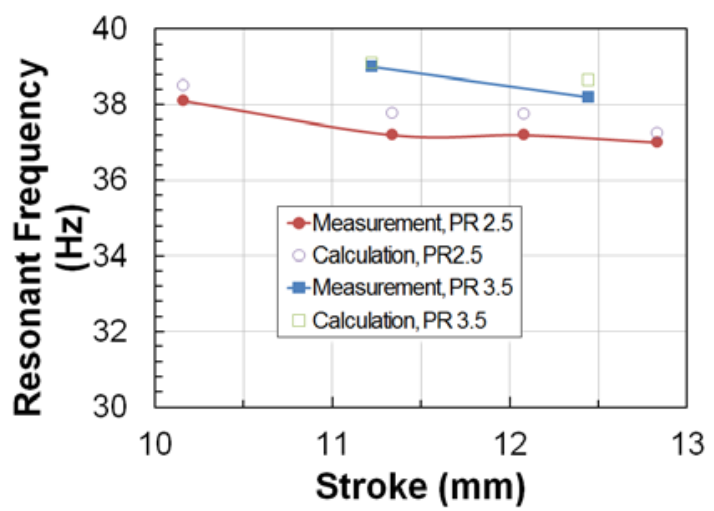

Fig. 4 Measured and calculated resonant frequency against stroke at different pressure ratios for R134a (PR: Pressure Ratio)

\section{Compressor Performance with R134a}

\subsection{Pressure-Volume Diagram}

The experimental results are separated into two parts: linear compressor performance and refrigeration system performance.

For each test condition, the cylinder pressure is not directly measured but can be derived from the force balance equations using the measured displacement, the current and the body pressure. Hence a pressure-volume diagram ( $P-V$ diagram) can be plotted for each test condition. The forces in the system comprise the motor force $F_{\text {motor }}$ (derived from the force-displacement-current map), the spring force $F_{\text {spring, }}$, the cylinder gas pressure force $F_{\text {cylinder }}$, the body pressure force $F_{\text {body }}$, and the damping force (or drag force) due to friction between the cylinder wall and the piston $F_{\text {damping. }}$ The force acting on the piston will be as follow

$$
m \ddot{x}=F_{\text {motor }}-F_{\text {spring }}-\left(F_{\text {cylinder }}-F_{\text {body }}\right)-F_{\text {damping }}
$$

where the cylinder pressure can be inferred since the body pressure, displacement, and current were measured. More details have been reported by Liang et al. (2013).

Fig. 5 shows the $P-V$ diagram for a stroke of $12 \mathrm{~mm}$, and a pressure ratio of 2.5 (evaporator temperature of $20^{\circ} \mathrm{C}$ ). The four processes (compression, discharge, expansion, and suction) can be identified from the $P-V$ diagram together with the measured discharge and suction line pressures.

Fig. 5 shows that the suction process takes longer than the discharge. This is because the volume flow rate needs to be higher in the suction process than in the discharge as the gas density during the suction stroke is lower than during the discharge stroke. The discharge valve opens (at the starting point of the measured discharge pressure line in Fig. 5) but the cylinder pressure keeps rising until the valve is fully opened. After the expansion process, the cylinder pressure drops to be lower than the suction pressure so that the suction valve opens. As the volume increases, the cylinder pressure decreases to its lowest point (about 4 bar). Once the suction valve has opened more, the cylinder pressure increases as the piston velocity is reducing. 


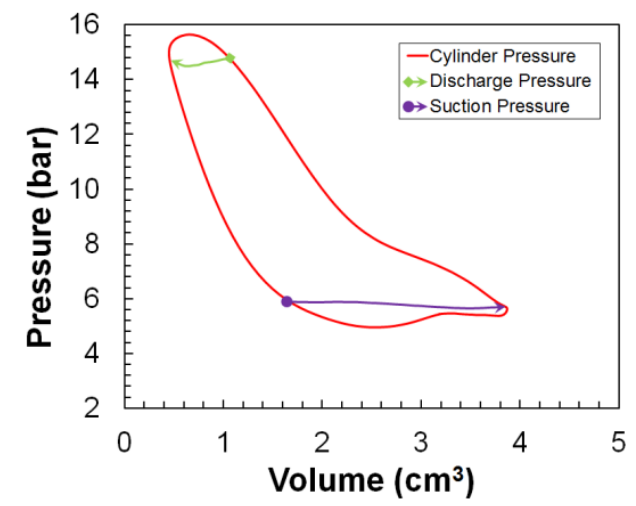

Fig. $5 \mathrm{P}-V$ diagram for a pressure ratio of 2.5 , and a stroke of $12 \mathrm{~mm}$ (evaporator temperature of $20^{\circ} \mathrm{C}$ ) using R134a

\subsection{Efficiencies}

Fig. 6 shows the compressor electrical power input variation with the stroke for different pressure ratios. It is seen that the power increases very linearly with the stroke. The maximum power input is approximately $152 \mathrm{~W}$. The power input decreases with an increasing pressure ratio for a fixed stroke, due to the decreasing evaporator pressure. The mass flow rate variation with the stroke at different pressure ratios is also plotted in Fig. 6. The mass flow rate increases with an increasing stroke fairly linearly. A higher pressure ratio leads to a smaller mass flow rate for a fixed stroke because the volumetric efficiency and the suction vapour density will be lower.

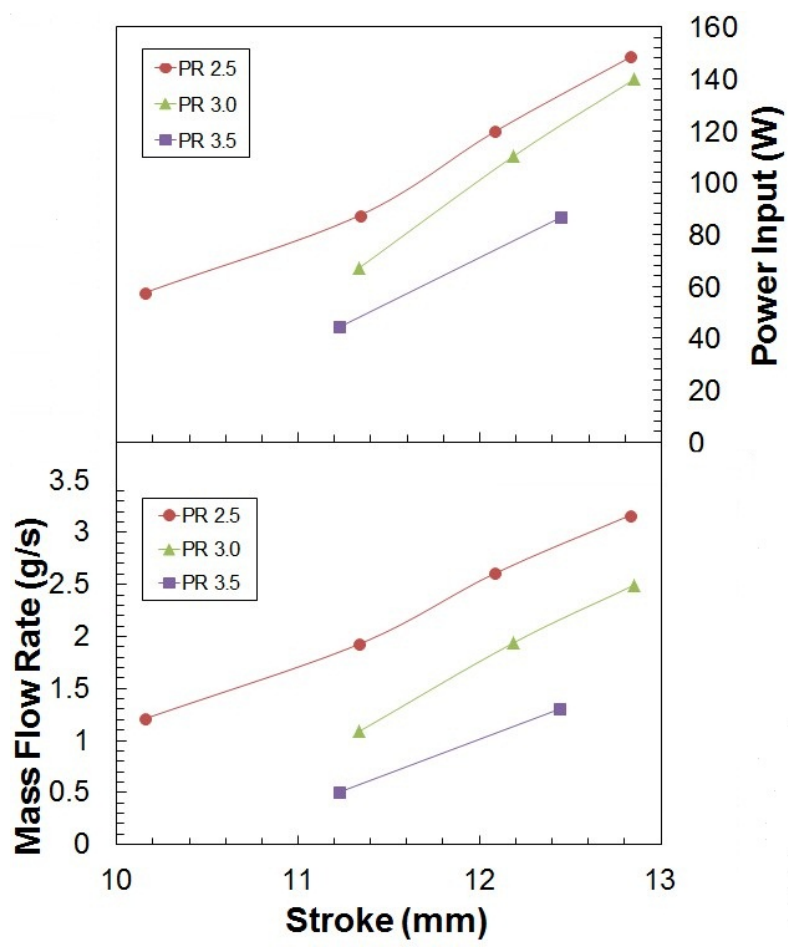

Fig. 6 Electrical power input and mass flow rate as a function of stroke for different pressure ratios using R134a with a condenser outlet temperature of $50^{\circ} \mathrm{C}$ (additional performance data are shown in

Fig. 11)

Fig. 7 shows the motor (electrical) efficiency and overall efficiencies as a function of stroke at each pressure ratio. The motor efficiency is the ratio of shaft power to the power input. The shaft power is 
the product of the shaft force (interpolated from the calibrated force-current-displacement map) and the differential of the measured piston displacement. The isentropic efficiency is defined as the ratio of isentropic power (constant entropy compression between suction and discharge pressures) to the electrical power input.

The motor efficiency decreases as the stroke increases for each pressure ratio, mainly because the copper losses ( $I$ squared $R$ losses) increase more rapidly than the shaft power as the drive current increases. Furthermore, for a fixed stroke, a higher pressure ratio gives a higher motor efficiency due to a higher drive frequency required for resonance.

The maximum motor efficiency is approximately $86 \%$ while the minimum is about $75 \%$. The motor efficiencies for pressure ratios of 2.5, 3.0 and 3.5 with a fixed stroke of $12 \mathrm{~mm}$ are $79 \%, 82 \%$ and $84 \%$ respectively. A commercial reciprocating compressor with similar capacity has been tested for comparison, which shows that the compressor efficiencies were very similar, but the linear motor was more efficient than the induction motor, particularly at low electrical power inputs. The motor efficiency is predicted to be higher than $86 \%$ with a revised design to reduce some of the eddy current losses (Liang et al., 2013a).

The isentropic efficiencies are also shown in Fig. 7. The maximum isentropic efficiency is about $44 \%$ when the linear compressor operates at a stroke of about $12 \mathrm{~mm}$ and a pressure ratio of 2.5. It is also seen that the isentropic efficiencies for different pressure ratios are closer at a higher stroke.

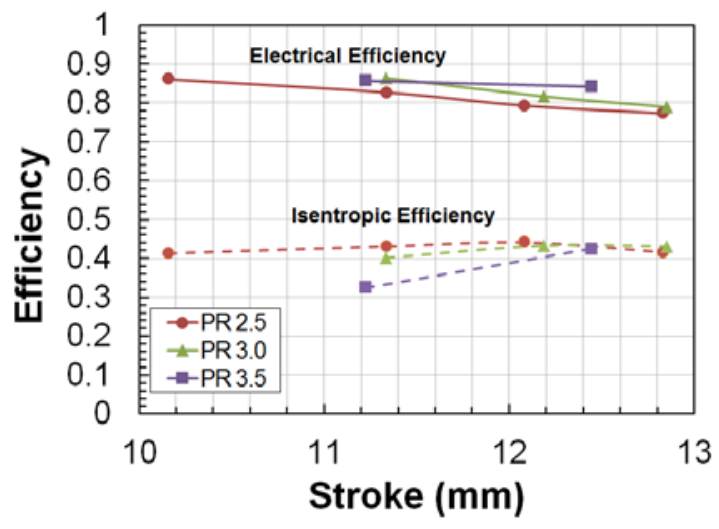

Fig. 7 Motor efficiency and isentropic efficiency dependency on stroke using R134a for a condenser outlet temperature of $50^{\circ} \mathrm{C}$

Fig. 8 shows the volumetric efficiency variation plotted against the stroke. To determine how the theoretical mass flow rate $\dot{m}$ depends on compressor geometry and its operation, the theoretical volumetric efficiency is given by:

$$
\eta_{\mathrm{V}}=1-C L\left[\left(\frac{P_{\mathrm{dis}}}{P_{\mathrm{suc}}}\right)^{\frac{1}{n}}-1\right]
$$

where $C L$ is the clearance (the ratio of clearance volume to swept volume) and $n$ is the polytropic index.

The experimental volumetric efficiency $\eta_{\mathrm{V}, \mathrm{e}}$, can be defined as

$$
\eta_{\mathrm{V}, \mathrm{e}}=\frac{\frac{\dot{m} R \mathrm{gT}_{\mathrm{suc}}}{P_{\mathrm{suc}}}}{S \cdot A \cdot f}
$$


It is seen that the experimental volumetric efficiency increases with an increasing stroke, due to the decreasing clearance volume as the mean piston position was fixed. For a fixed stroke, the higher pressure ratios have smaller volumetric efficiencies, and the maximum volumetric efficiency is about $43 \%$.

As a result of heat transfer during the suction process, flow restrictions in the valves, wall friction, seal leakage and other frictional losses, the experimental volumetric efficiency is much lower than the theoretical one. Fig. 8 shows that for a fixed pressure ratio of 2.5, the theoretical volumetric efficiency is about 2 times the experimental volumetric efficiency.

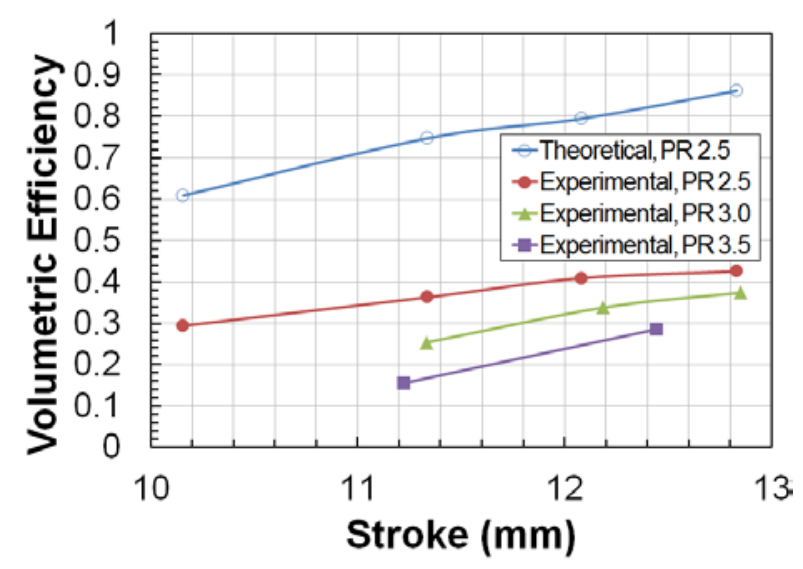

Fig. 8 Experimental and theoretical volumetric efficiency (with a polytropic index of 1.0) as a function of stroke for different pressure ratios using R134a

\section{Refrigeration Performance with R134a}

\subsection{Pressure-Enthalpy Diagram}

Fig. 9 shows the pressure-enthalpy $(p-h)$ diagram from measurements for a pressure ratio of 2.5 and a stroke of $12 \mathrm{~mm}$ (solid lines), which has an evaporator temperature of $20^{\circ} \mathrm{C}$ and a cooling capacity of $384 \mathrm{~W}$ (a typical operating condition for electronics cooling). The thermodynamic state variables of R134a came from the Peace Software (for online calculation of properties of fluid).

Relevant temperatures and pressures were measured to indicate the thermodynamic state of the refrigerant throughout the refrigeration cycle. However, the thermocouple for measuring the discharge temperature was not mounted on the outlet of the compressor but in the pipework between the compressor and the condenser. Therefore, the temperature at State 2 (Fig. 9) is estimated by assuming the compression process to be isentropic for the measured pressures and the isentropic power can then be calculated from the change in enthalpy

$$
\dot{W}_{\text {isen }}=\dot{m}\left(h_{2}-h_{1}\right)
$$

By analysing the $p$ - $h$ diagram in Fig. 9, the system cooling capacity can be calculated as follow

$$
\dot{Q}_{\text {cool }}=\dot{m}\left(h_{1}-h_{4}\right)
$$

If the refrigeration system operates under a fixed test condition, the enthalpies entering and exiting the evaporator will remain constant. 
Fig. 9 also shows a $p$-h diagram for a pressure ratio of 3.0 and stroke of $12 \mathrm{~mm}$ (dashed lines) which has an evaporator temperature of $9^{\circ} \mathrm{C}$ and a cooling capacity of $193 \mathrm{~W}$ with the same condenser outlet temperature $\left(50^{\circ} \mathrm{C}\right)$.

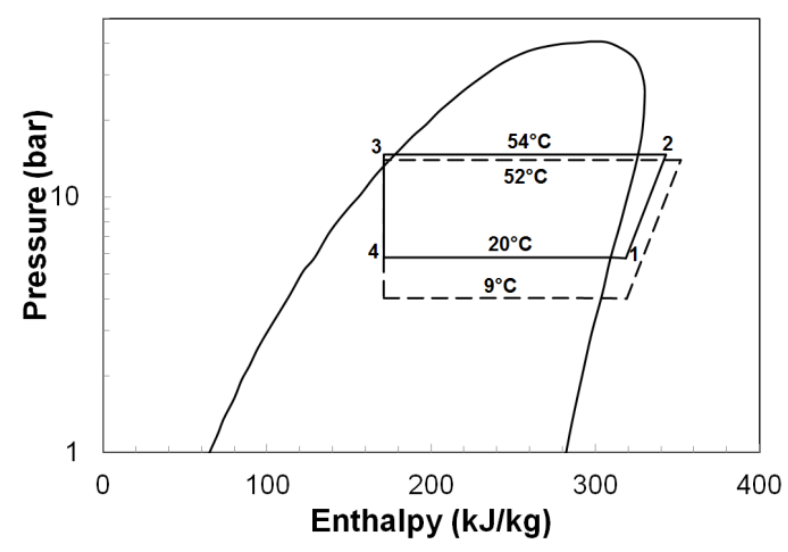

Fig. 9 Pressure-enthalpy plots for pressure ratios of 2.5 (solid) and 3.0 (dashed) for the same stroke of $12 \mathrm{~mm}$ with cooling capacities of $384 \mathrm{~W}$ and $193 \mathrm{~W}$, respectively

In steady-state system operation, the cooling capacity of the evaporator (based on the refrigerant measurements) is expected to be the same as the input power to the electrical heater. Fig. 10 shows a comparison of the measured electrical heat input and the calculated cooling capacity for tests with different pressure ratios. It is seen that close agreement is achieved with an average difference of about $11 \mathrm{~W}$, mainly due to heat transfer to or from the surroundings in the evaporator or the pipework adjacent to it. The good agreement helps to verify that the experimental data for each test condition were acquired under steady-state operation of the refrigeration system.

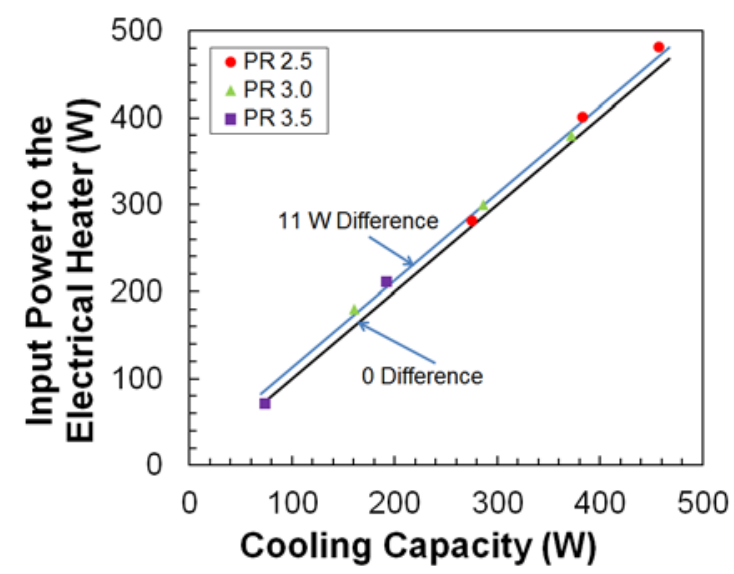

Fig. 10 Comparison of input power to the electrical heater and cooling capacity at different pressure ratios with a condenser outlet temperature of $50^{\circ} \mathrm{C}$

\subsection{Refrigeration Performance}

The evaporator temperature (saturation temperature from the measured evaporator inlet pressure) as a function of stroke and pressure ratio is shown in Fig. 11. The evaporator temperature increases with the increasing stroke for each fixed pressure ratio because the discharge pressure becomes higher as the stroke is increased. For operations with a similar stroke, the evaporator temperature decreases with increasing pressure ratio, due to the decreasing evaporator inlet pressure (very close to the suction pressure as the pressure drop across the evaporator is negligible). For the pressure ratio of 3.5, the 
lowest evaporator temperature of $6^{\circ} \mathrm{C}$ is achieved at a stroke of approximately $11 \mathrm{~mm}$. A typical CPU cooling condition (evaporating at around $20^{\circ} \mathrm{C}$ ) is obtained when the linear compressor operates at a pressure ratio of 2.5 .

The cooling capacity against the stroke at different pressure ratios is also shown in Fig. 11 . The cooling capacity follows a similar trend (fairly linear) to the evaporation temperature as a function of stroke and pressure ratio. This is because the cooling capacity itself increases with an increasing evaporator temperature. It can be seen that the maximum cooling capacity is about $458 \mathrm{~W}$ (evaporator temperature of $21^{\circ} \mathrm{C}$, pressure ratio of 2.5 , stroke of $13 \mathrm{~mm}$ ) and the lowest cooling capacity is about $75 \mathrm{~W}$ (evaporator temperature of $6^{\circ} \mathrm{C}$ ). The typical CPU cooling condition (evaporator temperature of $20^{\circ} \mathrm{C}$ ) achieves a cooling capacity of about $384 \mathrm{~W}$.

Fig. 11 shows the COP against the stroke for each pressure ratio. Overall, the COP increases with an increasing stroke for each pressure ratio. For a fixed stroke, the COP increases as the pressure ratio decreases because of the increasing evaporator temperature. The COP is approximately 3.2 when the compressor operates at a pressure ratio of 2.5 and stroke of $12 \mathrm{~mm}$ with an evaporator temperature of $20^{\circ} \mathrm{C}$. For different strokes at a pressure ratio of 2.5, the average COP is about 3.1, indicating a fairly good performance for the refrigeration system with the linear compressor. The average COP drops to about 2.6 for a pressure ratio of 3.0 because the evaporator temperature decreases from $20^{\circ} \mathrm{C}$ to about $15^{\circ} \mathrm{C}$. The lowest COP is about 1.7 when the evaporator temperature is $6^{\circ} \mathrm{C}$. 


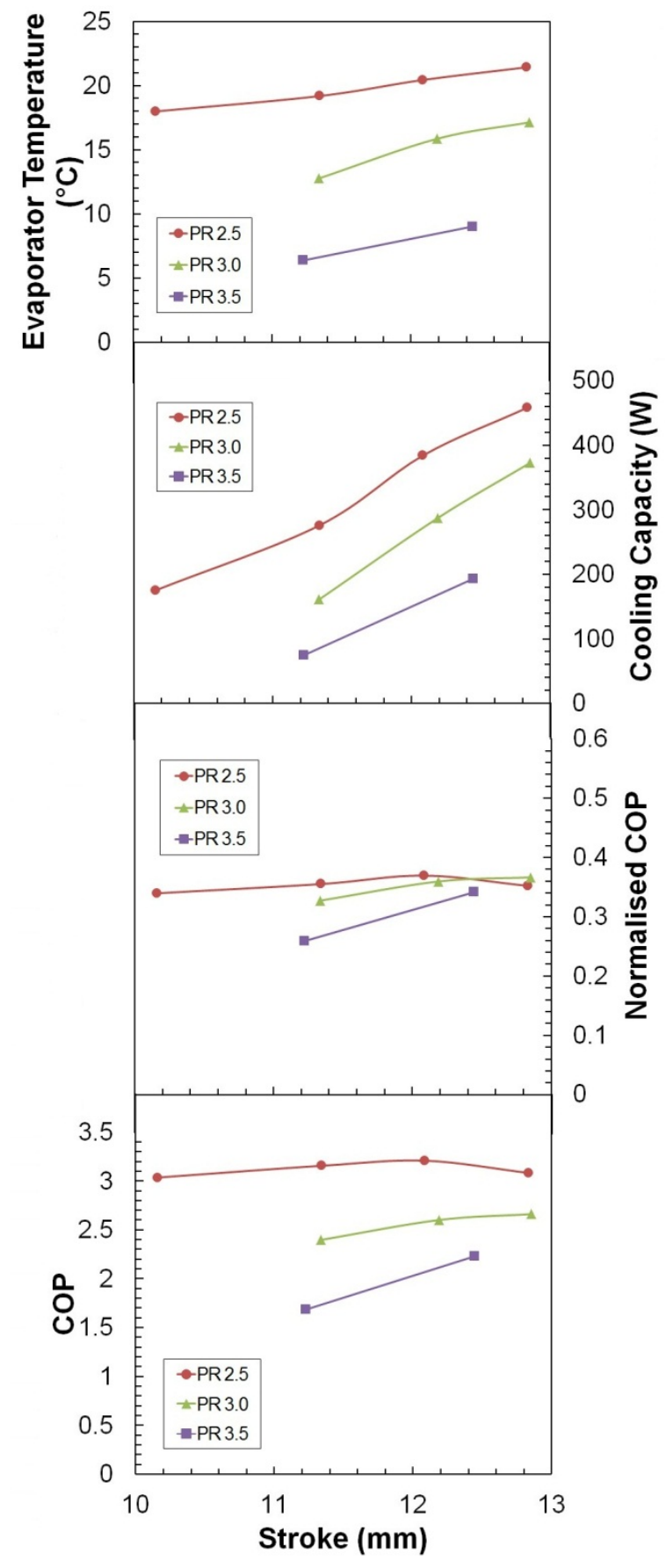

Fig. 11 Evaporator temperature, cooling capacity, COP and normalised COP variations with stroke at different pressure ratios (the mass flow rate and power input are plotted in Fig. 6)

Table 3 gives the experimental data for a pressure ratio of 2.5 and a stroke of $12 \mathrm{~mm}$ when the system operated with an evaporator temperature of $20^{\circ} \mathrm{C}$. This is a typical operating condition for CPU cooling. The COP is 3.2 for a cooling capacity of $384 \mathrm{~W}$, and a condenser temperature of $54^{\circ} \mathrm{C}$. The main aim of the linear compressor development for CPU cooling is to deliver the power specifications required for a system with a $250 \mathrm{~W}$ cooling capacity and an estimated system COP of 2.5 reported by Davies et al. (2010).

Table 3 Experimental parameters for pressure ratio of 2.5 and stroke of $12 \mathrm{~mm}$

Frequency $(\mathrm{Hz})$




\begin{tabular}{cc}
\hline Power input $(\mathrm{W})$ & 120 \\
Mass flow rate $\left(\mathrm{gs}^{-1}\right)$ & 2.6 \\
Evaporator inlet pressure (bar) & 5.8 \\
Condenser pressure (bar) & 14.7 \\
Body pressure (bar) & 8.4 \\
Suction temperature $\left({ }^{\circ} \mathrm{C}\right)$ & 30 \\
Saturated evaporator temperature $\left({ }^{\circ} \mathrm{C}\right)$ & 20 \\
Saturated condenser temperature $\left({ }^{\circ} \mathrm{C}\right)$ & 54 \\
Sub-cooling $(\mathrm{K})$ & 4.4 \\
Superheat $(\mathrm{K})$ & 10.0 \\
Cooling capacity $(\mathrm{W})$ & 384 \\
COP & 3.2 \\
\hline
\end{tabular}

For relative comparison to a reversible cycle, the COP of a Carnot refrigeration cycle is utilized, which is a function of the evaporation and condensation temperature (in Kelvin).

$$
C O P_{\text {Carnot }}=\frac{T_{\text {evap }}}{T_{\text {cond }}-T_{\text {evap }}}
$$

The normalised COP of the refrigeration system can be expressed in terms of the actual COP and the Carnot cycle COP.

$$
\varepsilon_{\text {Carnot }}=\frac{C O P}{\operatorname{COP}_{\text {Carnot }}}
$$

Fig. 11 plots the normalised COP of the refrigeration cycle against the stroke for each pressure ratio operation. Overall, the normalised COP does not change very much for each operating condition within a range of $0.33-0.37$, apart from the condition with a pressure ratio of 3.5 and a stroke of 11 $\mathrm{mm}$ (evaporator temperature of $6^{\circ} \mathrm{C}$ ) due to a very low COP of 1.7. For the operation with a pressure ratio of 2.5, the normalised COP is almost independent of the stroke, averaging about 0.35 . However, for each pressure ratio, it is seen that the normalised COP slightly increases as the stroke increases (note that the evaporator temperature increases as well).

The COP against the cooling capacity for each pressure ratio is shown in Fig. 12. Generally, the COP increases with increasing cooling capacity as the evaporator temperature rises. It is worth mentioning that in the calculation of cooling capacity, the amount of superheat was added as can be seen in Fig. 9. The cooling capacity excluding the superheat produces only an average difference of $4 \%$ in the COP calculation.

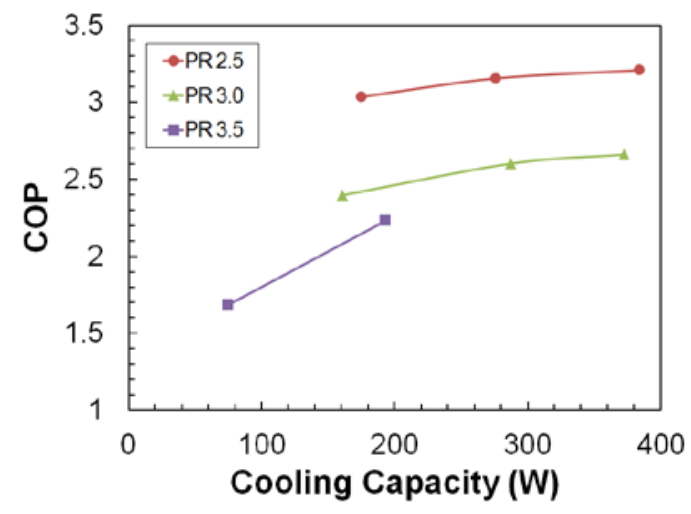


Fig. 12 COP as a function of cooling capacity at different pressure ratios with a condenser outlet temperature of $50^{\circ} \mathrm{C}$

\section{Off-resonance Performance}

A series of off-resonance measurements was conducted to investigate the effect of system resonance on the performance of the linear compressor and the refrigeration performance. The off-resonance tests were with a stroke of $11 \mathrm{~mm}$ and pressure ratio of 2.5, which achieved an evaporator temperature of approximately $19^{\circ} \mathrm{C}$. Previous measurements have shown that the measured resonant frequency was $38 \mathrm{~Hz}$. The drive frequency was adjusted from $36 \mathrm{~Hz}$ to $40 \mathrm{~Hz}$ in steps of $0.5 \mathrm{~Hz}$.

Fig. 13 shows the motor efficiency of the linear compressor against the drive frequency. The resonant frequency has the highest motor efficiency of $82 \%$. The motor efficiency follows a nearly symmetric trend across the frequency range. The motor efficiency decreases to about $78 \%$ when the drive frequency is $2 \mathrm{~Hz}$ away from the resonance.

The isentropic efficiency as a function of the drive frequency is also shown in Fig. 13. The highest isentropic efficiency (approximately 45\%) occurs at a drive frequency of $38 \mathrm{~Hz}$. The isentropic efficiency drops to $41 \%$ when the drive frequency decreases to $36 \mathrm{~Hz}$ or increases to $40 \mathrm{~Hz}$.

Fig. 13 gives the electrical power input and COP variations with the drive frequency. The least power input is $91.2 \mathrm{~W}$ at $38 \mathrm{~Hz}$. Overall, the power input has a symmetric trend against the drive frequency, increasing to $98.8 \mathrm{~W}$ at $40 \mathrm{~Hz}$ and $101.3 \mathrm{~W}$ at $36 \mathrm{~Hz}$. It can be seen that operating with a half $\mathrm{Hz}$ departure from resonance will consume 3\% more electrical power because the drive current is minimised at resonance to achieve the lowest copper loss.

The COP reflects the change in power input as a function of the drive frequency. The maximum COP of 3.4 is achieved at resonance. The COP decreases from the peak value to approximately 3.0 in both directions with a frequency difference of $2 \mathrm{~Hz}$. It is seen that a $5 \%$ change in the drive frequency away from the resonance requires $11 \%$ extra electrical power input and reduces the COP by $12 \%$. These off-resonance measurements verify the importance of operating the linear compressor at resonance. However, as the efficiency/frequency curves are fairly flat, it is not necessary to be very precise in choosing the operating frequency. 


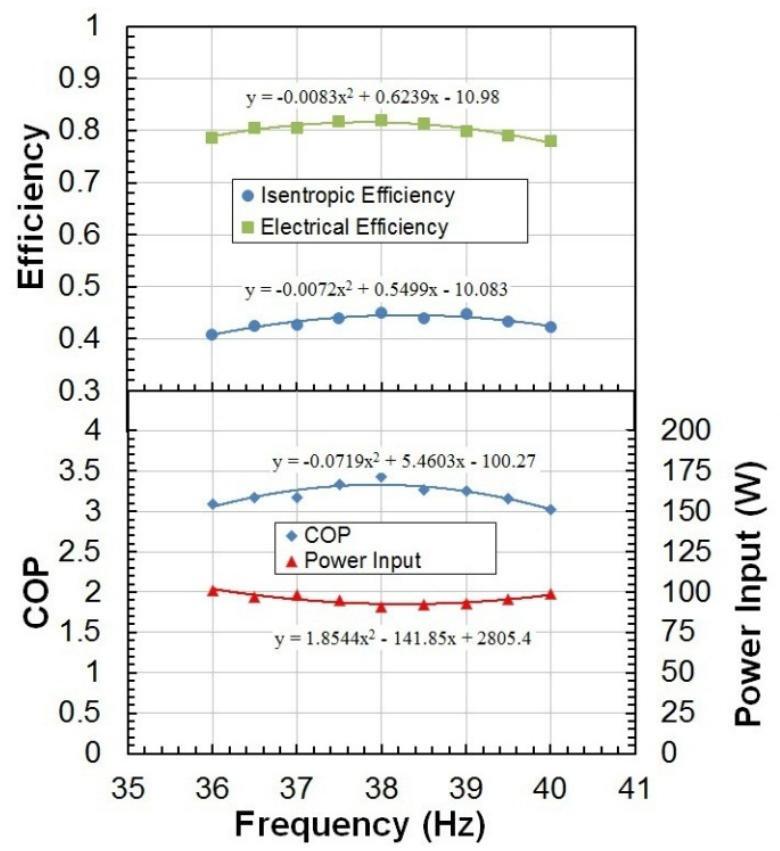

Fig. 13 Compressor efficiencies, COP and power input against frequency for a stroke of $11 \mathrm{~mm}$ and pressure ratio of 2.5 with an evaporator temperature of $19^{\circ} \mathrm{C}$ and a condenser outlet temperature of $50^{\circ} \mathrm{C}$

\section{Conclusions}

A prototype moving magnet linear compressor has been tested with R134a in a refrigeration system.

(1) Resonant frequencies from the calculation are very similar to the measured frequencies, with a difference of about $1.5 \%$.

(2) The motor efficiency ranges from $75 \%$ to $86 \%$ and the isentropic efficiency varies from $32 \%$ to $44 \%$, indicating a good compressor performance, comparable to the previous nitrogen test results (Liang et al. 2013b).

(3) The measured evaporator temperature falls between $6^{\circ} \mathrm{C}$ to $21^{\circ} \mathrm{C}$ when the linear compressor operates at different strokes (11 mm to $13 \mathrm{~mm}$ ) for each pressure ratio with a constant condenser outlet temperature of $50^{\circ} \mathrm{C}$. The COP ranges from 1.7 to 3.2.

(4) A COP of 3.2 is achieved at a cooling capacity of $384 \mathrm{~W}$ with an evaporator temperature of $20^{\circ} \mathrm{C}$ and a condenser temperature of $54^{\circ} \mathrm{C}$. This is assumed to be a typical CPU cooling condition. The performance data has met the requirements of the preliminary aim of a system for CPU cooling.

(5) Off-resonance measurements under a particular refrigeration condition show that the linear motor efficiency reduces by $4 \%$ when the drive frequency is $2 \mathrm{~Hz}$ different from the resonant frequency. A $5 \%$ change of the drive frequency away from resonance requires $11 \%$ extra electrical power and reduces the COP by $12 \%$. This indicates that the linear compressor should be operated at resonance for a high efficiency.

\section{Acknowledgements}

The authors acknowledge The Engineering and Physical Sciences Research Council (EPSRC) for funding the design and construction of the linear compressor (Grant Ref EP/E036899/1).

\section{References}


Bailey, P.B., Dadd, M.W., and Stone, C.R., 2009. An oil-free linear compressor for use with compact heat exchangers. In: Proceedings of International Conference on Compressors and their Systems, Institute of Mechanical Engineering, London, pp. 259-268.

Bailey, P.B., Dadd, M.W., and Stone, C.R., 2011. Cool and straight: linear compressors for refrigeration. In: Proceedings of Institute of Refrigeration, 4-1.

Barbosa, J.R., Ribeiro, G.B., and de Oliveira, P.A., 2012. A state-of-the-art review of compact vapour compression refrigeration systems and their applications. Heat Transfer Engineering, 33 (4-5), pp. 356-374.

Bradshaw, C.R., Groll, E.A., and Garimella, S.V., 2011. A comprehensive model of miniature-scale linear compressor for electronics cooling. Int. J. Refrigeration, 34, pp. 63-73.

Bradshaw, C.R., 2012. A miniature-scale linear compressor for electronics cooling. Ph.D. Thesis, Purdue University.

Bradshaw, C.R., Groll, E.A., and Garimella, S.V., 2012. Linear compressors for electronics cooling: energy recovery and the useful benefits. In: Proceedings of International Compressor Engineering Conference, Purdue, 1134, pp. 1-10.

Chen, N., Tang, Y.-j., Wu, Y.-n., Chen, X., and Xu L., 2007. Study on static and dynamic characteristics of moving magnet linear compressors. Cryogenics, 47, pp. 457-467.

Davies, G.F., Eames, I.W., Bailey, P.B, Dadd, M.W., Janiszewski, A., Stone, C.R., Maidment, G.G., and Agnew, B., 2010. Cooling microprocessors using vapour compression refrigeration. In: Thermal and Thermomechanical Phenomena in Electronics Systems (ITherm), $12^{\text {th }}$ IEEE Intersociety Conference, Las Vegas, pp. 1-8.

http://www.h2wtech.com/Pages/Product-Detail.aspx?prodid=112 (accessed 20/1/2013).

http://www.peacesoftware.de/einigewerte/r134a_e.html (accessed 20/11/2012).

Kim, H., Roh, C.-g., Kim, J.-k, Shin, J.-m, Hwang, Y., and Lee, J.-k, 2009. An experimental and numerical study on dynamic characteristic of linear compressor in refrigeration system. Int. J. Refrigeration, 32, pp. 1536-1543.

Liang, K., Dadd, M.W., and Bailey, P.B., 2013a. Clearance seal compressors with linear motor drive - part i: background and system analysis. In: Proceedings of Institute of Mechanical Engineering, Part A: Journal of Power and Energy, 227(3), pp. 242-251.

Liang, K., Dadd, M.W., and Bailey, P.B., 2013b. Clearance seal compressors with linear motor drive - part ii: experimental evaluation of an oil-free compressor. In: Proceedings of Institute of Mechanical Engineering, Part A: Journal of Power and Energy, 227(3), pp. 252-260.

Possamai, F., Lilie, D.E.B., Zimmermann, A.J.P., and Mongia, R., 2008. Miniature vapour compression system. In: Proceedings of International Compressor Engineering Conference, Purdue, 2392, pp. 1-8.

Unger, R., and Novotny, S., 2002. A high performance linear compressor for CPU cooling. In: Proceedings of International Compressor Engineering Conference, Purdue, C23-3.

http://www.peacesoftware.de/einigewerte/r134a_e.html. 